\title{
Molecular Mechanisms of Heterotopic Ossification
}

\author{
Lee M. Reichel, MD, Elizabeth Salisbury, PhD, Michael J. Moustoukas, MD, Alan R. Davis, \\ PhD, and Elizabeth Olmsted-Davis, PhD \\ Department of Orthopedic Surgery, Ben Taub General Hospital; and the Center for Cell and Gene \\ Therapy, Department of Orthopedic Surgery, Baylor College of Medicine, Houston, TX
}

First described in the early 1800 s, heterotopic ossification (HO) refers to the formation of extraskeletal bone. ${ }^{1}$ In the upper extremity, $\mathrm{HO}$ most frequently occurs after injury to the elbow, and can result in severe functional impairment (Fig. 1). A variety of factors have been implicated, including elbow dislocation, open injury, severe chest injury, longer wait time to surgery, and prolonged immobilization. 2,3 "Terrible triad" complex elbow fracture dislocations and distal humeral fractures have the highest rates of HO. ${ }^{3}$ A spectrum of $\mathrm{HO}$ formation exists after elbow injury, with more severe $\mathrm{HO}$ being associated with greater functional loss. Although associated injuries, radiographic findings, and clinical implications have been well documented, the molecular mechanisms have not pervaded the surgical literature. In the past several years, important advancements in our understanding of molecular mechanisms behind $\mathrm{HO}$ have been made.

\section{MOLECULAR PATHWAYS}

Heterotopic ossification or de novo bone formation involves recruitment and expansion of chondroosseous progenitors capable of undergoing bone formation in nonskeletal tissues. The initial inflammatory response and generation of a permissive tissue microenvironment appear critical for the induction of $\mathrm{HO}$. We $\mathrm{W}^{4}$ and others ${ }^{5}$ have shown that bone morphogenic proteine2 (BMP-2) initiates inflammation by release of neuroinflammatory factors substance $\mathrm{P}$ and calcitonin gene-related peptide (CGRP) from sensory nerves. These factors, in turn, recruit immune cells including mast cells, platelets, and neutrophils. ${ }^{4}$ Mast cell degranulation releases various proteases ${ }^{4}$ and activates matrix metalloproteinases ${ }^{6}$ that aid in remodeling the local peripheral nerves. This remodeling process enables not only the expansion and release of progenitors from the nerve, ${ }^{4}$ but also other accessory cells essential for patterning and coordinating the bone formation process, thus ensuring the vascularization and innervation of the newly formed bone. ${ }^{7}$ Inhibition of mast cell degranulation substantially reduces heterotopic bone formation. ${ }^{4}$

This neuroinflammatory process also leads to activation of sympathetic signaling via local serotonin release by mast cells, which ultimately leads to an elevation of norepinephrine in blood $^{7}$ and the activation and expansion of a brown adipocyte-like progenitor within the perineurial layer of the nerve. ${ }^{7}$ Like their endoneurial progenitor counterparts, these

(C) 2014 ASSH Published by Elsevier, Inc. All rights reserved.

Corresponding author: Lee M. Reichel, MD, Department of Orthopedic Surgery, Baylor College of Medicine, Ben Taub General Hospital, 1504 Taub Loop, Houston, TX 77030; leereichel@gmail.com.. 
perineurial progenitors migrate from the nerves to the site of new bone formation. The perineurial progenitors differentiate into brown fatlike cells, which create a hypoxic microenvironment, thus lowering local oxygen levels necessary for chondrogenesis. ${ }^{8}$ In addition, these cells express vascular endothelial growth factors that promote vessel formation, raising local oxygen levels needed for osteogenesis and contributing to the vascularization of HO. ${ }^{9}$ A subset of these brown fat cells also express the neural guidance molecule reelin, which facilitates the critical innervation of the newly formed bone. ${ }^{7}$ It is likely that these pathways interact and are tightly controlled by hypoxia inducible factor $1 a$.

It was previously believed that the progenitors for bone formation were marrow mesenchymal stem cells. ${ }^{10}$ However, recent work suggests local stem or progenitor cells contribute to $\mathrm{HO}$.

\section{LITERATURE REVIEW}

The literature has suggested that muscle satellite cells ${ }^{11}$ or smooth muscle cells ${ }^{12}$ might undergo chondroosseous differentiation. However, through lineage tracing for the hematopoietic-endothelial marker Tie2, Lounev et a ${ }^{13}$ demonstrated the presence of a reporter in the immature fibroproliferative cells as well as the chondrogenic and osteogenic cells within $\mathrm{HO}$, which suggests that the cells were endothelial in origin. They also found that the smooth muscle marker, smooth muscle myosin heavy chain and skeletal muscle marker were observed in less than $5 \%$ of the cells. Opposing this theory, Wosczyna et al ${ }^{11}$ suggested that the Tie-2 progenitor is distinct from the endothelium and resides in the interstitial region of skeletal muscle. They demonstrated that neither the native endothelial cells nor the endogenously delivered endothelial cells exposed to BMP-2 participated in HO. Using a similar lineage tracing model, the authors purified a Tie $2^{+} \mathrm{PDGFRa}{ }^{+} \mathrm{Sca}-1^{+}$ progenitor from skeletal muscle that appeared to expand upon implantation of rBMP-2 in Matrigel and undergo both osteogenic and adipogenic differentiation. ${ }^{11}$ Distinguishing them from previously described muscle stem cell populations, these progenitors were negative for pericyte markers, did not share a basal lamina with the adjacent endothelium, and appeared to be a completely distinct cell population. In support of these findings, studies of human heterotopic ossification in the military population suggest the presence of a muscle derived mesenchymal stem cell. ${ }^{14}$

As noted, the authors identified chondro-osseous progenitors that appear to arise from a different local soft tissue, peripheral nerves. ${ }^{4}$ In these studies, a progenitor cell within the endoneurium of the nerve was identified that expresses the stem cell markers Nanog and $\mathrm{Klf} 4$, as well as the osterix transcription factor specific for the osteoblasts. In addition, these cells express several endothelial markers. These cells expand and migrate out of the peripheral nerve and to the muscle interstitium toward the site of new bone formation. We propose that the cells identified by others in muscle with endothelial-like markers ${ }^{11}$ may ultimately be derived from the specialized endothelium within the endoneurium ${ }^{4}$ as well as perineurium ${ }^{7,8}$ of sensory nerves. 


\section{MEDICAL THERAPY}

Current medical therapy for heterotopic ossification has not been overwhelmingly successful. Standard anti-inflammatory agents, particularly indomethacin, have been used with some success. In addition, there are several clinical trials evaluating the efficacy of the Cox2 inhibitors, but these have been mainly related to hip arthroplasty. Based on our current model (Fig. 2), there may be other drugs, some of which are already licensed, that could effectively and selectively suppress neurogenic inflammation and eliminate HO. ${ }^{4,5}$ Such drugs include capsaicin, an inhibitor of transient receptor potential cation channel, subfamily $\mathrm{V}$, member 1, as well as other transient receptor potential cation channel, subfamily $\mathrm{V}$, member 1 inhibitors, some of which are in late-phase clinical trials for other indications ${ }^{15}$ or inhibitors that block binding of substance $\mathrm{P}$ to its receptor. ${ }^{5}$ In addition, we have found that an inhibitor of mast cell degranulation, cromolyn, also prevents $\mathrm{HO}$ in an animal model. ${ }^{4}$ However, cromolyn has problems related to oral bioavailability, which may be overcome using the drug Gastrocrom (Meda Pharmaceuticals, Somerset, NJ). We believe the best drugs will target the earliest molecular events in $\mathrm{HO}$, preventing the problem before it becomes established. This emphasizes the importance of detailed understanding of the molecular mechanisms underlying HO. The next steps include human studies to confirm the neural origin of some bone-forming cells. Second, clinical trials are needed of HOpreventing therapeutic agents, as mentioned above, some of which are already licensed for other indications.

\section{REFERENCES}

1. Puzas EJ, Miller MD, Rosier RN. Pathologic Bone Formation. Clin Orthop Relat Res. 1989; (245): 269-281. [PubMed: 2502346]

2. Bauer AS, Lawson BK, Bliss RL, Dyer GSM. Risk factors for posttraumatic heterotopic ossification of the elbow: case-control study. J Hand Surg Am. 2012; 37(7):1422-1429. [PubMed: 22551954]

3. Foruira AM, Augustin S, Morrey BF, Sanchez-Sotelo J. Heterotopic ossification after surgery for fractures and fracture-dislocations involving the proximal aspect of the radius or ulna. J Bone Joint Surg Am. 2013; 95(10):e661-e667.

4. Salisbury E, Rodenberg E, Sonnet C, et al. Sensory nerve induced inflammation contributes to heterotopic ossification. J Cell Biochem. 2011; 112(10):2748-2758. [PubMed: 21678472]

5. Kan L, Kitterman JA, Procissi D, et al. CNS demyelination in fibrodysplasia ossificans progressive. J Neurol. 2012; 259(12):2644-2655. [PubMed: 22736080]

6. Rodenberg E, Azhdarinia A, Lazard ZQ, et al. Matrix metal-loproteinase-9 is a diagnostic marker of heterotopic ossification in a murine model. Tissue Eng Part A. 2011; 17(19-20):2487-2496. [PubMed: 21599541]

7. Salisbury EA, Lazard ZW, Ubogu EE, Davis AR, Olmsted-Davis EA. Transient brown adipocytelike cells derive from peripheral nerve progenitors in response to bone morphogenetic protein 2. Stem Cells Transl Med. 2012; 1(12):874-885. [PubMed: 23283549]

8. Olmsted-Davis E, Gannon FH, Ozen M, et al. Hypoxic adipocytes pattern early heterotopic bone formation. Am J Pathol. 2007; 170(2):620-632. [PubMed: 17255330]

9. Dilling CF, Wada AM, Lazard ZW, et al. Vessel formation is induced prior to the appearance of cartilage in BMP-2-mediated heterotopic ossification. J Bone Miner Res. 2010; 25(5):1147-1156. [PubMed: 19839764]

10. Pittenger MF, Mackay AM, Beck SC, et al. Multilineage potential of adult human mesenchymal stem cells. Science. 1999; 284(5411):143-147. [PubMed: 10102814] 
11. Wosczyna MN, Biswas AA, Cogswell CA, Goldhamer DJ. Multi-potent progenitors resident in the skeletal muscle interstitium exhibit robust BMP-dependent osteogenic activity and mediate heterotopic ossification. J Bone Miner Res. 2012; 27(5):1004-1017. [PubMed: 22307978]

12. Cairns DM, Liu R, Sen M, et al. Interplay of Nkx3.2, Sox 9 and Pax3 regulates chondrogenic differentiation of muscle progenitor cells. PLoS One. 2012; 7(7):e39642. [PubMed: 22768305]

13. Lounev VY, Ramachandran R, Wosczyna MN, et al. Identification of progenitor cells that contribute to heterotopic skeletogenesis. J Bone Joint Surg Am. 2009; 91(3):652-663. [PubMed: 19255227]

14. Jackson WM, Aragon AB, Bulken-Hoover JD, et al. Putative heterotopic ossification progenitor cells derived from traumatized muscle. J Orthop Res. 2009; 27(12):1645-1651. [PubMed: 19517576]

15. Gunthorpe MJ, Chizh BA. Clinical development of TRPV1 antagonists: targeting a pivotal point in the pain pathway. Drug Discov Today. 2009; 14(1-2):56-67. [PubMed: 19063991] 

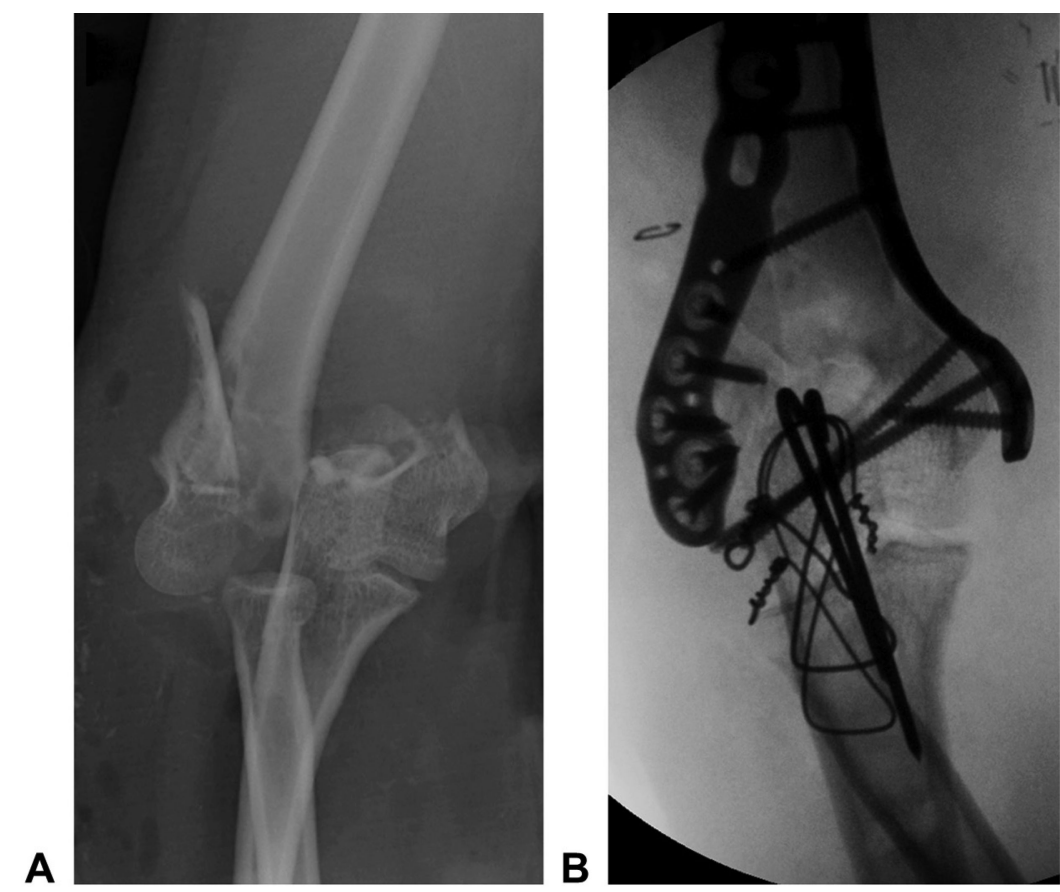

A
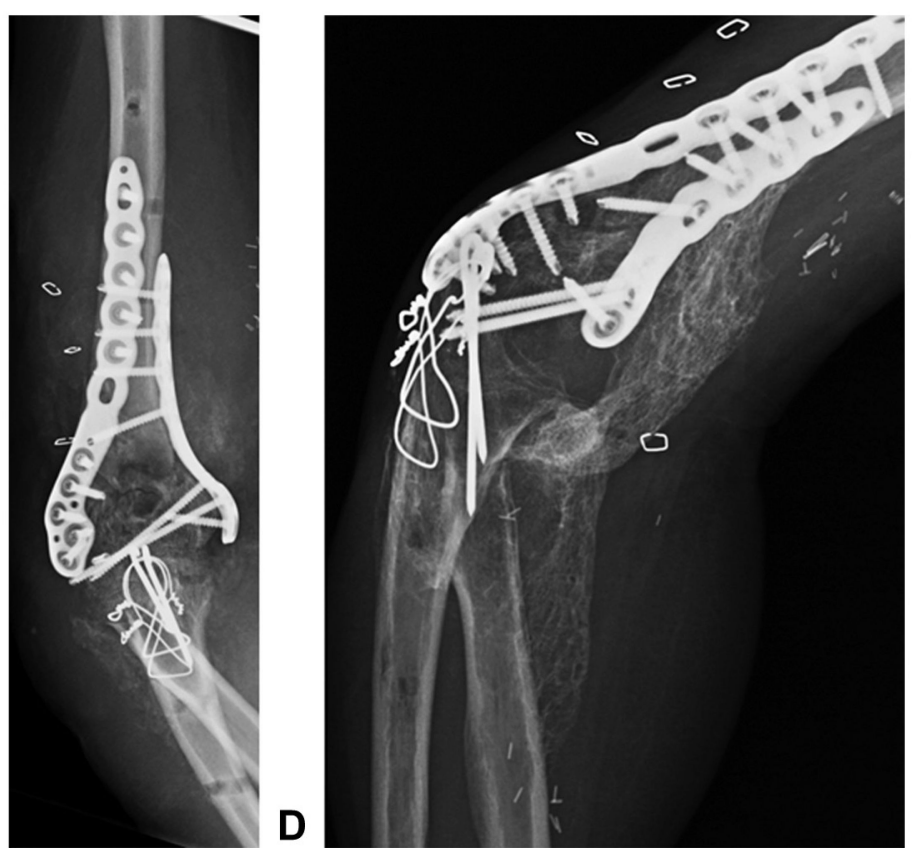

FIGURE 1.

High-energy elbow injury resulting in ankylosed elbow joint secondary to HO. A injury. B Intraoperative reduction and stabilization. C Early HO. D Mature bridging HO resulting in ankylosed joint. 


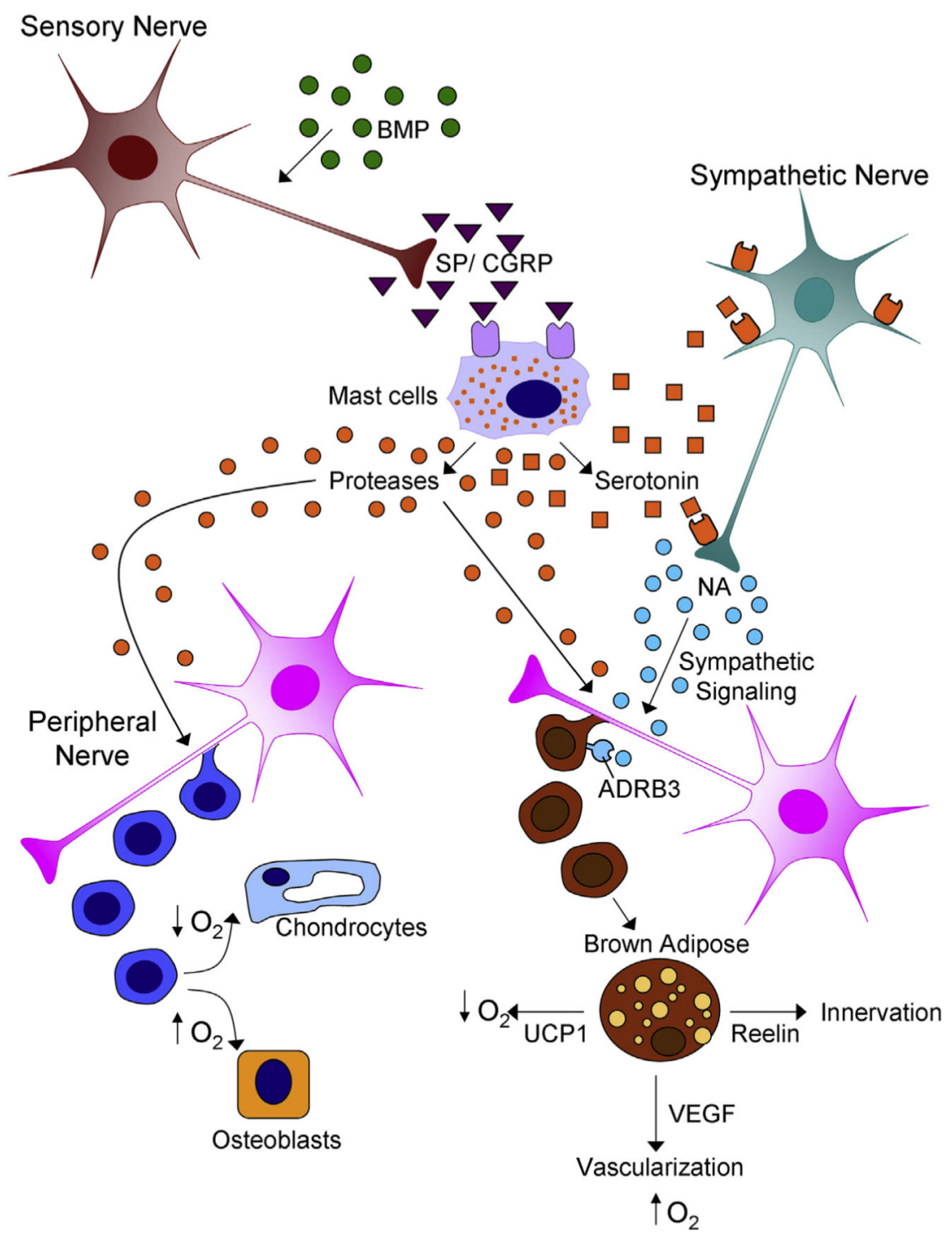

FIGURE 2.

How sensory nerves initiate heterotopic ossification. The initial target of BMP-2 is the sensory nerve itself. Binding to its receptor on these nerves activates the synthesis of substance $\mathrm{P}$ and CGRP. Binding of substance $\mathrm{P}$ and CGRP to their respective receptors on mast cells is the next step in the cascade of neurogenic inflammation. The ultimate goal of this cascade is to both activate remodeling of these peripheral nerves as well as initiate the production of chondro-osseous, glial, vascular, and neural progenitors within the nerve. Mast cells then secrete proteases (eg, chymase 1) that further activate the inflammatory cascade through other cells, particularly platelets and neutrophils, which begin to break down the nerve, including the blood nerve interface, for ultimate release of progenitors. Mast cells also release serotonin, which activates sympathetic signaling through release of noradrenaline. We found that the transient brown adipocyte is a key cell in the regulation of bone formation, and the $\beta 3$ adrenergic receptor, through binding of noradrenaline, is critical for the formation of transient brown fat cells. These cells regulate microenvironmental 
oxygen tension, which is necessary for the initiation of chondrogenesis by lowering local oxygen levels. This process is mediated by uncoupling protein 1 . These cells also secrete vascular endothelial growth factor, which initiates the synthesis of new vessels that contain newly formed osteoblast progenitors ready for delivery to calcified cartilage. Cells released from peripheral nerves contain progenitors for both chondrocytes and osteoblasts. However, these nerves also release progenitors for glial cells, both Schwann cells and reelin-positive astrocyte-like cells, to ensure that the newly formed bone is both innervated and vascularized. NA, noradrenaline; SP/CGRP, substance P/calcitonin gene-related peptide; ADRB3, beta-3 adrenergic receptor; UCP1, uncoupling protein 1; VEGF, vascular endothelial growth factor. 